\title{
Correlation between Insulin Resistance and LVEF in non Diabetic Chronic Heart Failure Patients admitted in a Tertiary Care Hospital
}

\author{
MD. AZHARUL ISLAM ${ }^{1}$, MANZOOR MAHMOOD ${ }^{1}$, KHURSHED AHMED ${ }^{1}$, SAJAL KRISHNA BANERJEE ${ }^{1}$, SYED ALI \\ AHSAN ${ }^{1}$, CHAUDHURY MESHKAT AHMED ${ }^{1}$, A.K.M. IMTIAZ AKAND ${ }^{1}$, SUJOY KUMAR SAHA ${ }^{1}$, FYSAL FARUQ ${ }^{1}$, \\ KAMRUZZMAN SIDDIKI ${ }^{1}$, AKM FAZLUR RAHMAN', MD. FAKHRUL ISLAM KHALED ${ }^{1}$, SM MUSTAFAZAMAN ${ }^{\text {, }}$ \\ FARIDA YEASMIN ${ }^{2}$, PARVEENAKTER ${ }^{3}$, MD. HARISUL HOQUE ${ }^{1}$ \\ ${ }^{1}$ Department of Cardiology, Bangabandhu Sheikh Mujib Medical University, Dhaka, ${ }^{2}$ Department of Nuclear Medicine, National \\ Institute of Nuclear Medicine and Allied Science, Shahbagh, Dhaka, ${ }^{3}$ Kurmitola General Hospital, Dhaka, \\ Address of Correspondent: Dr. Md. Azharul Islam, Resident (Phase-B), Department of Cardiology, Bangabandhu Sheikh Mujib \\ Medical University, Dhaka, Email: azharulrafi28@gmail.com.
}

\begin{abstract}
:
Background: Insulin resistance is a well-established composite index of systemic inflammatory and metabolic disorders. A wide variety of methods like, HOMA-IR (Homeostatic model assessment insulin resistance), FGIR (Fasting glucose insulin ratio), ISI-Composite (an index of whole body insulin sensitivity), QUICKI (quantitative insulin sensitivity check index) etc are available for assessing IR.

Objective: To find out the correlation between insulin resistance and LVEF in non diabetic chronic heart failure patients.

Methodology: This cross sectional study was carried out in the Department of Cardiology in Bangabandhu Sheikh Mujib Medical University, Shahbagh, Dhaka from February, 2019 to June, 2020. Patients admitted with chronic heart failure with reduced ejection fraction were included in this study. Patients with diabetic, prediabetic and patient who did not give written informed consent were excluded in this study.

Results: LVEF 25-29\% was 16 patients out of which 10(66.7\%) had significant insulin resistance. LVEF 30$34 \%$ was found in 28 patients, among them 16(41.0\%) had no insulin resistance. LVEF 35-39\% was found in 19 patients out of which $18(46.2 \%)$ had no insulin resistance. The difference was statistically significant $(p<0.05)$. A negative correlation $(r=-0.340 ; p=0.006)$ was found between insulin resistance and LVEF.

Conclusion: Majority non diabetic chronic heart failure patients had no insulin resistance. Significant negative correlation was found between insulin resistance and LVEF.
\end{abstract}

University Heart Journal 2021; 17(2): 99- 102

Introduction:

Heat failure (HF) occurs in individuals with diabetes at higher rates, even in the absence of other HF risk factors such as coronary artery disease and hypertension. Patients with HF are also at risk of developing incident diabetes over time. The high prevalence of ischemic heart disease and cardiovascular risk factors significantly contribute to the development of cardiomyopathy and HF in patients with diabetes. ${ }^{1}$ As Bangladesh is a developing country heat failure contributing a major health burden to the society. World wide the incidence of heart failure is variable but increasing with advancing age. Approximately 26 million people world wide are suffering from heart failure. ${ }^{2}$ Effective modulation of some heart failure-related outcomes with metformin treatment was related to its beneficial effects in ameliorating insulin resistance and blocking pro-inflammatory markers such as the agingassociated cytokine CCL11 (C-C motif chemokine ligand 11). ${ }^{3}$ Insulin resistance is a well-established composite index of systemic inflammatory and metabolic disorders. Mounting evidence reveals that insulin resistance predicts and, to some extent, mediates the development of atherosclerosis, myocardial infarction and in-stent restenosis. The predictive role of insulin resistance for LV remodeling and incident $\mathrm{CHF}$ has also been proposed. Especially, a unique concentric LV remodeling pattern was 
characterized in relatively healthy subjects with insulin resistance. ${ }^{4}$ A wide variety of methods like, HOMA-IR (Homeostatic model assessment insulin resistance), FGIR (Fasting glucose insulin ratio), ISI-Composite (an index of whole body insulin sensitivity), QUICKI (quantitative insulin sensitivity check index) etc are available for assessing IR. But simpler and inexpensive methods may be appropriate provided the investigator is aware of their limitations. ${ }^{5}$ This study has been planned to investigate the presence of abnormalities of insulin sensitivity in non diabetic chronic heart failure patients with reduced ejection fraction. ${ }^{5}$

\section{Methodology:}

This cross sectional study was carried out in the Department of Cardiology in Bangabandhu Sheikh Mujib Medical University, Shahbagh, Dhaka during February, 2019 to June, 2020. Patients admitted with chronic heart failure with reduced ejection fraction were included in this study. Patients with diabetic, prediabetic and patient who did not give written informed consent were excluded in this study. After getting consent, meticulous history including demographic data (such as age, sex), risk factors profile including smoking, hypertension, diabetes, dyslipidemia, family history of ischemic heart disease were taken and relevant clinical examinations (general, cardiovascular and respiratory) were performed and recorded in a pre designed structured proforma. Standard 12 lead ECG was recorded at a $25 \mathrm{~mm} / \mathrm{s}$ paper speed and a gain of $10 \mathrm{~mm} / \mathrm{mV}$ with the patient fully relaxed in the supine position. CXR P/A was done. Transthoracic echocardiography was done to assess the RWMA, LV dysfunction, LVEF. Other laboratory investigations such as fasting insulin level, fasting and 2-h after breakfast blood glucose level, HbA1c, Fasting lipid profile, S.creatinine were done. Insulin resistance was calculated by using HOMA-IR formula (HOMA-IR > 1.9 and HOMAIR $>2.9$ considered as early and significant insulin resistance). Separate data collection sheet was used for each subject with maintaining confidentiality. Highest level of confidentiality and ethical standard was maintained during storage and analysis of the data. Data was collected according to the pre designed semistructured data collection sheet. Statistical analyses were carried out by using the Statistical Package for Social Sciences (SPSS) version 23.0 for Windows Software. Continuous data were expressed as mean \pm standard deviation (SD) and categorical data were expressed as frequency and percentages. Mean and standard deviation were calculated for quantitative variables and was analyzed by Bonferroni Test. Chi square test was used for categorical variables. The association of LVEF with insulin resistance was done by Pearson's correlation coefficient test. $\mathrm{P}$ values $<0.05$ was considered as statistically significant.

\section{Results:}

Out of 63 patients, male were predominant 41(65.1\%) with male-female ratio was 1.8:1. Mean age was found 59.65 \pm 8.52 years with range from 42 to 80 years. Mean BMI was $23.18 \pm 2.39 \mathrm{~kg} / \mathrm{m}^{2}$ with range from 18.3 to $29.5 \mathrm{~kg} / \mathrm{m}^{2}$. Regarding co-morbidities majority patients had hypertension $40(63.5 \%)$ followed by dyslipidemia $37(58.7 \%)$, history of myocardial infarction $32(50.8 \%)$, smoking 29(46.0\%), family history of IHD 17(27.0\%) and obesity $11(17.5 \%$ ) (Table-1). Regarding left ventricular ejection fraction (LVEF) in this study most of the patients had LVEF 30-34\%, 28(44.4\%) followed by 19(30.2\%) were LVEF 35-39\% and 16(25.4\%) were LVEF 25-29\% (Fiugre-1). Most of the patients 39(61.9\%) had no insulin resistance, $15(23.8 \%)$ of patients had significant insulin resistance and $9(14.3 \%)$ patients had early insulin resistance (Table2). LVEF $25-29 \%$ was found in 16 patients out of which $10(66.7 \%)$ had significant insulin resistance. LVEF 30-34\% was found in 28 patients, among them $16(41.0 \%)$ had no insulin resistance. LVEF $35-39 \%$ was found in 19 patients out of which $18(46.2 \%)$ had no insulin resistance. The difference was statistically significant $(\mathrm{p}<0.05)$ (Table-3). A negative correlation $(\mathrm{r}=-0.340 ; \mathrm{p}=0.006)$ between LVEF and insulin resistance (Figure-2).

Table-I

Baseline characteristics of study patients $(n=63)$

\begin{tabular}{lcc}
\hline Parameters & Frequency & Percentage \\
\hline Gender & & \\
$\quad$ Male & 41 & 65.1 \\
$\quad$ Female & $59.65 \pm 8.52$ & 34.9 \\
Mean age (years) & $23.18 \pm 2.39$ & \\
Mean BMI (kg/m ${ }^{2}$ ) & & \\
Co-morbidities & 40 & 63.5 \\
$\quad$ Hypertension & 37 & 58.7 \\
$\quad$ Dyslipidemia & 32 & 50.8 \\
H/O of myocardial infarction & 29 & 46.0 \\
$\quad$ Smoking & 17 & 27.0 \\
Family history of IHD & 11 & 17.5 \\
$\quad$ Obesity & & \\
\hline
\end{tabular}




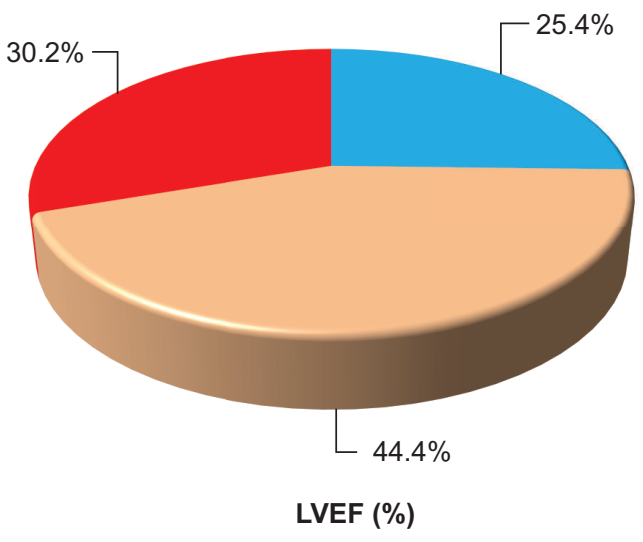

Fig.-1: Pie chart showing LVEF of the study patients $(n=63)$

Table-II

Prevalence of insulin resistance of the study patients $(n=63)$

\begin{tabular}{lcc}
\hline Insulin resistance & Frequency & Percentage \\
\hline No resistance & 39 & 61.9 \\
Early resistance & 9 & 14.3 \\
Significant resistance & 15 & 23.8 \\
\hline
\end{tabular}

Table-III

Relation between LVEF with Insulin Resistance

\begin{tabular}{lccccc}
\hline LVEF & $\begin{array}{c}c \\
\text { No } \\
\text { resistance } \\
\mathrm{n}=39(\%)\end{array}$ & $\begin{array}{c}\text { Early } \\
\text { resistancen } \\
\mathrm{n}=9(\%)\end{array}$ & $\begin{array}{c}\text { Significant } \\
\text { resistancen } \\
\mathrm{n}=15(\%)\end{array}$ & Total & p value \\
\hline $25-29 \%$ & $5(12.8)$ & $1(11.1)$ & $10(66.7)$ & 16 & $0.001^{\mathrm{s}}$ \\
$30-34 \%$ & $16(41.0)$ & $7(77.8)$ & $5(33.3)$ & 28 & \\
$35-39 \%$ & $18(46.2)$ & $1(11.1)$ & $0(0.0)$ & 19 & \\
\hline Total & $39(100)$ & $9(100)$ & $15(100)$ & 63 & \\
\hline
\end{tabular}

$\mathrm{s}=$ significant; $\mathrm{p}$ value reached from Chi square test

$$
r=-0.340 ; p=0.006
$$

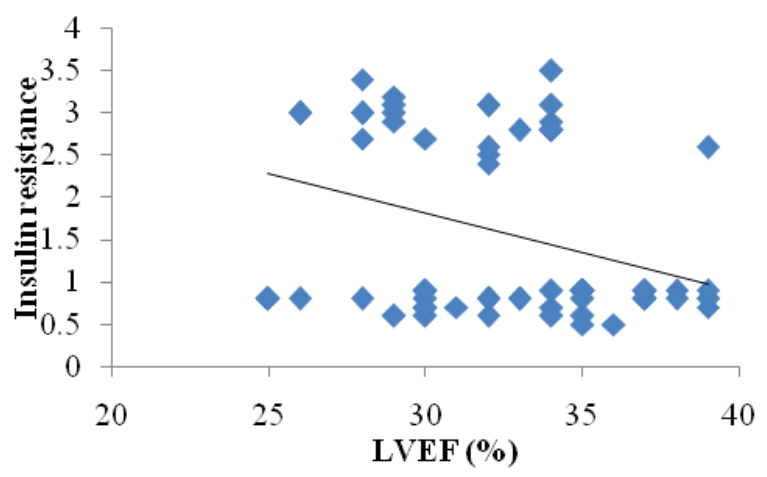

Fig.-2: Scatter diagram showing negative correlation between LVEF and insulin resistance.

\section{Discussion:}

In this study out of 63 patients, male were predominant $41(65.1 \%)$ with male-female ratio was 1.8:1. Al-Jarallah et al. ${ }^{6}$ reported $60.0 \%$ of the patients were male. ALZadjali et al. ${ }^{7}$ reported male was found $76.0 \%$ and female was $24.0 \%$. Julián et al. ${ }^{8}$ found male was $78.5 \%$. In Vafaeimanesh et al. ${ }^{9}$ study, 120 non-diabetic cases were evaluated and $53.5 \%$ were males which also support our study.

In our study mean age were $59.65 \pm 8.52$ years with range from 42 to 80 years. Al-Jarallah et al. ${ }^{6}$ study reported the mean age was $63.0 \pm 11.0$ years, ranging from 18 to 99 years. ALZadjali et al. ${ }^{7}$ also supported our observation. They found mean age(+-SD) was found $69.2 \pm 10.4$ years. Vafaeimanesh et al. ${ }^{9}$ also found similar observation. They showed the average age of the population was $57.8 \pm 12.69$ years and $60 \%$ of them were $50-70$ years old. Julián et al. ${ }^{8}$ reported the mean age was $64 \pm 13.2$ years.

We found that mean BMI was $23.18 \pm 2.39 \mathrm{~kg} / \mathrm{m}^{2}$ with range from 18.3 to $29.5 \mathrm{~kg} / \mathrm{m}^{2}$. Bahijri et al. ${ }^{10}$ found 113 subjects (87.7\%), were either obese or overweight; and 73 (54.1\%) had abdominal obesity ( $>102$ and $>88 \mathrm{~cm}$ for males and females, respectively). In contrast, subjects in the LIR subgroup had normal BMI, and none suffered from abdominal obesity. Julián et al. ${ }^{8}$ found the mean BMI was $27.7 \mathrm{~kg} / \mathrm{m}^{2}$. Al-Jarallah et al. ${ }^{6}$ found the mean BMI was $29.7 \pm 6.6 \mathrm{~kg} / \mathrm{m}^{2}$ which is almost as our finding.

Regarding co-morbidities majority patients had hypertension $40(63.5 \%)$ followed by dyslipidemia $37(58.7 \%)$, history of myocardial infarction $32(50.8 \%)$, smoking 29(46.0\%), family history of IHD 17927.0\%) and obesity $11(17.5 \%)$. In study of Al-Jarallah et al. ${ }^{6}$ showed $1843(81.6 \%)$ patients had hypertension and $1228(54.4 \%)$ patients had dyslipidemia. Julián et al. ${ }^{8}$ reported previous history of myocardial infarction was $43.8 \%$.

In the study, it was found that most $28(44.4 \%)$ of the patients had LVEF $30-34 \%$ followed by $19(30.2 \%)$ were LVEF $35-39 \%$ and 16(25.4\%) were LVEF 25-29\%. Al-Jarallah et al. ${ }^{6}$ reported the mean EF was 35\% (25-45\%). Julián et al. ${ }^{8}$ observed that the mean LVEF was found $30.4 \pm 8.4 \%$.

In our study showed most of the patients 39(61.9\%) had no insulin resistance, $15(23.8 \%)$ of patients had significant insulin resistance and $9(14.3 \%)$ patients had early insulin resistance. Vafaeimanesh et al. ${ }^{9}$ reported $66(55 \%)$ patients had insulin resistance (HOMA-IR> 2.5) and 54 (45\%) patients did not have insulin resistance. Bahijri et al. ${ }^{10}$ observed 135 subjects (64.6\% of the studied population) were considered to have high insulin resistance. 
We found that LVEF $25-29 \%$ was 16 patients out of which $10(66.7 \%)$ had significant resistance. LVEF $30-34 \%$ was found in 28 patients. Among them 16(41.0\%) had no insulin resistance. LVEF 35-39\% was observed in 19 patients out of which 18(46.2\%) had no insulin resistance. The difference was statistically significant $(p<0.05)$. Swan et al. ${ }^{11}$ found that patients with ischemic heart disease and normal left ventricular function were insulin resistant and hyperinsulinemic but to a significantly lesser degree than patients with CHF due to ischemic heart disease. This finding supports the suggestion that the abnormalities of insulin metabolism occur secondary to the heart failure itself, possibly resulting from circulatory changes or as part of the overall neurohormonal response to heart failure.

We found a negative correlation $(\mathrm{r}=-0.340 ; \mathrm{p}=0.006)$ between insulin resistance and LVEF. Scherbakov et al. ${ }^{12}$ reported additionally, linear regression analyses revealed an association of fasting IR with $\mathrm{HFpEF}(r=0.64, P<0.01)$. So, insulin resistance is associated with heart failure both $\mathrm{HFpEF}$ and HFpEF, although a negative correlation is established between LVEF and insulin resistance by this study.

\section{Conclusion:}

Majority non diabetic chronic heart failure patients had no insulin resistance. Significant negative correlation was found between insulin resistance and LVEF.

\section{Reference:}

1. Oktay AA, Aktürk HK, Paul TK, O'Keefe JH, Ventura HO, Koch CA, Lavie CJ. Diabetes, Cardiomyopathy, and Heart Failure. Endotext [Internet] 2020 Aug 1.

2. Ambrosy AP, Fonarow GC, Butler J, Chioncel O, Greene SJ, Vaduganathan M, Nodari S, Lam CS, Sato N, Shah AN, Gheorghiade M. The global health and economic burden of hospitalizations for heart failure: lessons learned from hospitalized heart failure registries. Journal of the American College of Cardiology. 2014;63(12):1123-33.

3. Dludla PV, Nyambuya TM, Johnson R, Silvestri S, Orlando P, Mazibuko-Mbeje SE, Gabuza KB, Mxinwa V, Mokgalaboni K, Tiano L, Muller CJ. Metformin and heart failure-related outcomes in patients with or without diabetes: a systematic review of randomized controlled trials. Heart Failure Reviews. 2020 Mar 10:1-9.

4. Yang CD, Shen Y, Lu L, Ding FH, Yang ZK, Zhang RY, Shen WF, Jin W, Wang XQ. Insulin resistance and dysglycemia are associated with left ventricular remodeling after myocardial infarction in non-diabetic patients. Cardiovascular diabetology. 2019;18(1):100..

5. Borai A, Livingstone C, Kaddam I, Ferns G. Selection of the appropriate method for the assessment of insulin resistance. BMC medical research methodology. 2011;11(1):158.

6. Al-Jarallah M, Rajan R, Al-Zakwani I, Dashti R, Bulbanat B, Ridha M, Sulaiman K, Alsheikh-Ali AA, Panduranga P, AlHabib KF, Al Suwaidi J. Mortality and Morbidity in HFrEF, HFmrEF, and HFpEF Patients with Diabetes in the Middle East. Oman Medical Journal. 2020;35(1):e99.

7. ALZadjali MA, Godfrey V, Khan F, Choy A, Doney AS, Wong AK, Petrie JR, Struthers AD, Lang CC. Insulin resistance is highly prevalent and is associated with reduced exercise tolerance in nondiabetic patients with heart failure. Journal of the American College of Cardiology. 2009;53(9):747-53.

8. Julián MT, Alonso N, Lupón J, Gavidia-Bovadilla G, Ferrer E, de Antonio M, López-Ayerbe J, Domingo M, Santiago-Vacas E, Zamora E, Codina P. Long-term LVEF trajectories in patients with type 2 diabetes and heart failure: diabetic cardiomyopathy may underlie functional decline. Cardiovascular diabetology. 2020;19:1-1.

9. Vafaeimanesh J, Parham M, Norouzi S, Hamednasimi P, Bagherzadeh M. Insulin resistance and coronary artery disease in non-diabetic patients: Is there any correlation?. Caspian journal of internal medicine. 2018;9(2):121..

10. Bahijri SM, Alissa EM, Akbar DH, Ghabrah TM. Estimation of insulin resistance in non-diabetic normotensive Saudi adults by QUICKI, HOMA-IR and modified QUICKI: a comparative study. Annals of Saudi medicine. 2010;30(4):257-64.

11. Swan JW, Anker SD, Walton C, Godsland IF, Clark AL, Leyva F, Stevenson JC, Coats AJ. Insulin resistance in chronic heart failure: relation to severity and etiology of heart failure. Journal of the American College of Cardiology. 1997;30(2):527-32..

12. Scherbakov N, Bauer M, Sandek A, Szabó T, Töpper A, Jankowska EA, Springer J, Von Haehling S, Anker SD, Lainscak $\mathrm{M}$, Engeli S. Insulin resistance in heart failure: differences between patients with reduced and preserved left ventricular ejection fraction. European journal of heart failure. 2015;17(10):1015-21. 